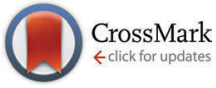

Cite this: Chem. Commun., 2017. 53,2483

Received 25th January 2017, Accepted 6th February 2017

DOI: $10.1039 / c 7 c c 00727 b$

rsc.li/chemcomm

\section{Neutral iodotriazole foldamers as tetradentate halogen bonding anion receptors $\dagger$}

\author{
Arseni Borissov, Jason Y. C. Lim, Asha Brown, Kirsten E. Christensen, \\ Amber L. Thompson, Martin D. Smith and Paul D. Beer*
}

Neutral tetradentate halogen bond donor foldamers were synthesised and exhibit enhanced anion affinities over their hydrogen bonding analogues, displaying iodide selectivity over lighter halide, carboxylate and dihydrogen phosphate anions. A foldamer with a chiral (S)-binaphthol motif was demonstrated to distinguish between enantiomers of chiral anions.

Halogen bonding $(\mathrm{XB})$ is the attractive non-covalent interaction between a terminal $\sigma$-hole on an electron deficient halogen atom and a Lewis base. ${ }^{1}$ Its strength and directionality have led to several applications in materials science and, more recently, in supramolecular chemistry ${ }^{2,3}$ and organocatalysis. ${ }^{4}$ In particular, $\mathrm{XB}$ donors have been successfully used in anion receptors for molecular recognition and sensing applications. ${ }^{5}$ Many of these have shown enhanced binding properties over their hydrogen bonding (HB) analogues. 6,7

The electron-deficient ${ }^{8}$ 1,2,3-triazole motif has been exploited for anion recognition as an effective $\mathrm{C}-\mathrm{H}$ hydrogen bond donor when integrated into multidentate macrocycles ${ }^{9}$ and acyclic foldamers. ${ }^{10-12}$ While the related 5-iodotriazole unit has been used as $\mathrm{XB}$ donor for anion binding, such $\mathrm{XB}$ anion hosts are rare in the literature. ${ }^{13}$ No tetradentate $\mathrm{XB}$ donor foldamers have been described to date; the closest examples are a tridentate halopyridinium $^{14}$ and the use of triazole foldamers as $\mathrm{XB}$ acceptor hosts for organohalogens. ${ }^{15}$

Herein we sought to apply the potency of XB to enhance the anion affinity of the known triazole-based $\mathrm{HB}$ foldamer framework. Thus, XB foldamers with four 5-iodo-1,2,3-triazole XB donors were synthesized (Fig. 1) and their anion binding properties probed in comparison with $\mathrm{HB}$ analogues. A few variants were prepared: 1 and 2 contain triethylene glycol (TEG) chains for improved solubility, while in $\mathbf{3}$ and 4 9-anthrylmethyl termini have

Chemistry Research Laboratory, Department of Chemistry, University of Oxford, Mansfield Road, Oxford, OX1 3TA, UK. E-mail: paul.beer@chem.ox.ac.uk

$\dagger$ Electronic supplementary information (ESI) available: Compound data, crystal data for 3b-NaI, details of anion binding studies. CCDC 1529410. For ESI and crystallographic data in CIF or other electronic format see DOI: 10.1039/ c7cc00727b
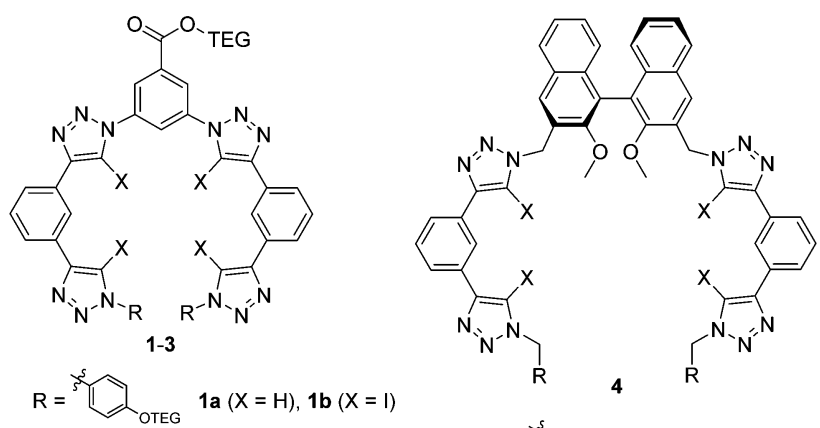

$R=2 a(X=H), 2 b(X=I)$
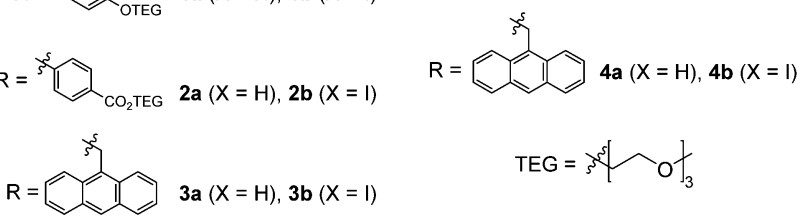

$\mathrm{TEG}=3^{5} \widehat{\mathrm{O}}_{3}$

Fig. 1 Structures of the $\mathrm{XB}$ and $\mathrm{HB}$ anion receptors 1-4.

been introduced to provide a fluorescent response. ${ }^{15,16}$ System 4 also includes a chiral $(S)$-binaphthol core in order to investigate $\mathrm{XB}$ chiral recognition, which has only previously been observed in a bidentate receptor. ${ }^{17}$ Importantly, the $\mathrm{XB}$ foldamers exhibited overall stronger anion affinity than their $\mathrm{HB}$ analogs with the chiral XB host $\mathbf{4 b}$ displaying chiral discrimination with bulky amino acid anions.

$\mathrm{XB}$ and $\mathrm{HB}$ foldamers 1-4 were synthesized via $\mathrm{Cu}(\mathrm{I})$-catalysed azide-(iodo)alkyne cycloaddition (CuAAC) reactions (Scheme 1) using $\mathrm{Cu}(\mathrm{MeCN})_{4} \mathrm{PF}_{6}$ in the presence of tris(benzyltriazolylmethyl) amine (TBTA) ligand. For the preparation of $\mathbf{1 a}$ and $\mathbf{2 a}$ an alternative benzyltriazolylmethylamine (BTA) ligand ${ }^{18}$ was used as these compounds co-eluted with TBTA during chromatographic purification. As seen in Scheme 1, a terminal azide synthon 5-7 was reacted statistically with an excess of bis-alkyne $\mathbf{8 a}$ or $\mathbf{8 b}$ to afford an arm fragment 9-11. Two equivalents of 9-11 were then coupled under CuAAC conditions with a bis-azide core synthon $\mathbf{1 2}$ or $\mathbf{1 3}$ to give the anion receptors 1-4. The cycloadditions proceeded in moderate to high yields of $64-88 \%$ for $5 H$-triazole and $46-85 \%$ for $5 I$-triazole formation (see ESI $\dagger$ for full synthetic details). 

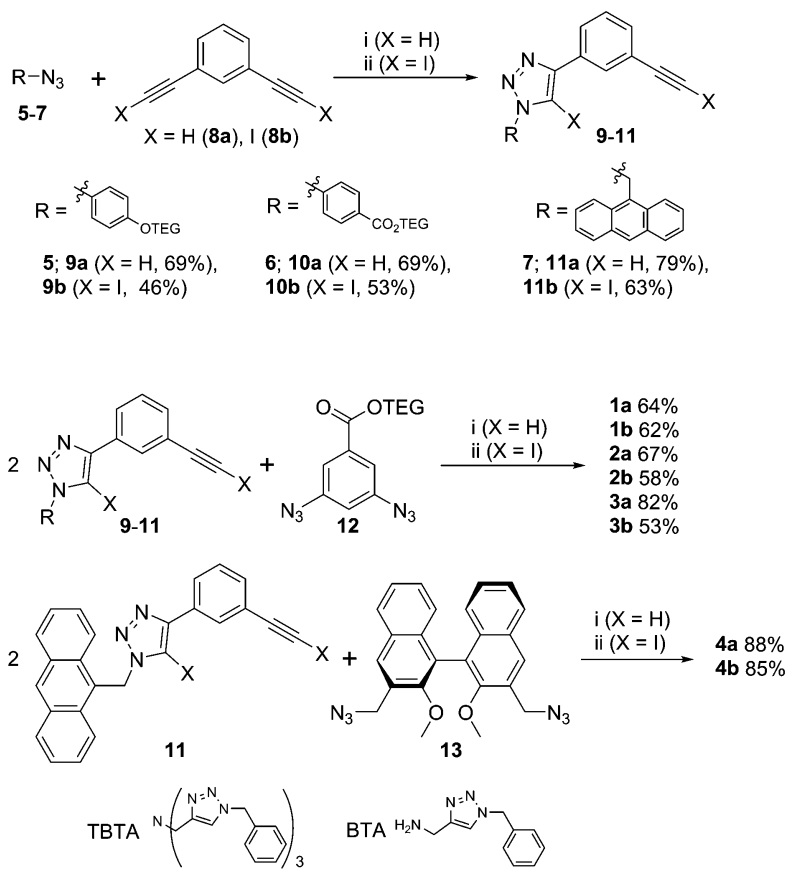

Scheme 1 Synthesis of the anion receptors 1-4. Reaction conditions: (i) 0.05 eq. $\mathrm{Cu}(\mathrm{MeCN})_{4} \mathrm{PF}_{6}, 0.05$ eq. TBTA or BTA, 0.1 eq. DIPEA, DCM, rt; (ii) 0.1 eq. $\mathrm{Cu}(\mathrm{MeCN})_{4} \mathrm{PF}_{6}, 0.1$ eq. TBTA, THF, rt, darkness.

The anion binding properties of $\mathbf{1 - 4}$ were studied by ${ }^{1} \mathrm{H}$ NMR titrations by adding increasing amounts of different anions as tetrabutylammonium (TBA) salts and monitoring changes in ${ }^{1} \mathrm{H}$ NMR spectra. For the HB receptors 1a-4a large downfield shifts $(\Delta \delta)$ of up to $2 \mathrm{ppm}$ were observed for the triazole protons $\mathrm{H}_{\mathrm{A}}$ and $\mathrm{H}_{\mathrm{B}}$; while smaller $\Delta \delta$ of $0.4-0.5 \mathrm{ppm}$ occurred for the phenylene protons $\mathrm{H}_{\mathrm{C}}$ and $\mathrm{H}_{\mathrm{E}}$ (Fig. 2). This is consistent with the known binding mode of tetradentate triazole $\mathrm{HB}$ receptors ${ }^{10}$ wherein the triazole protons and the phenylene ortho protons all contribute to guest complexation. Binding isotherms were obtained by monitoring $\mathrm{H}_{\mathrm{A}}$ signals and 1:1 stoichiometric association constants calculated using WinEQNMR2 software. ${ }^{19}$

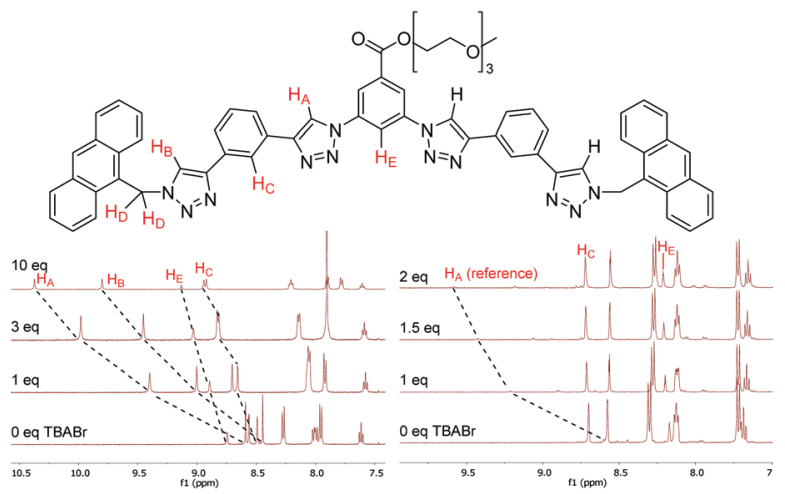

Fig. 2 Top: Labeling of protons monitored in ${ }^{1} \mathrm{H}$ NMR anion binding studies (consistent across 1-4). Bottom left: Partial ${ }^{1} \mathrm{H}$ NMR spectra of 2a titrated with TBABr. Bottom right: Partial ${ }^{1} \mathrm{H}$ NMR spectra of a competition experiment where $\mathbf{2} \mathbf{b}$ with $5 \mathrm{~mol} \%$ of $\mathbf{2} \mathbf{a}$ as reference is titrated with $\operatorname{TBABr}\left(500 \mathrm{MHz}, \mathrm{CDCl}_{3}, 298 \mathrm{~K}\right)$.
In the case of $\mathrm{XB}$ foldamers $\mathbf{1 b}-\mathbf{4 b}$ only small downfield perturbations $\Delta \delta$ of $0.03-0.2 \mathrm{ppm}$ were observed for the ortho phenylene protons $\mathrm{H}_{\mathrm{C}}$ and $\mathrm{H}_{\mathrm{E}}$. This is most likely due to the large size of the receptors' iodine atoms binding the guest anion at a significant distance from these protons (vide infra). Upfield shifts of similar magnitude were also observed for the aromatic and methylene protons in the terminal groups. Due to very small $\Delta \delta$ values reliable association constants could not be obtained for 1b-3b using the standard ${ }^{1} \mathrm{H}$ NMR titration protocol. Therefore, 1b-3b were instead analysed using a host-host competition binding method similar to approaches previously employed to study alkali metal complexation with crown ethers. ${ }^{20}$ In a typical experiment a small amount (5 $\mathrm{mol} \%)$ of $\mathrm{HB}$ receptor $2 \mathrm{a}$ was added to the solution of a XB compound $\mathbf{1 b} \mathbf{b} \mathbf{3} \mathbf{b}$ as a reference. Changes of the reference compound $\mathrm{H}_{\mathrm{A}}$ signals upon anion addition were then monitored (Fig. 2), which enabled reliable association constant data to be determined for $\mathbf{1} \mathbf{b}-\mathbf{3 b}$ (see $\mathrm{ESI} \dagger$ for full details). While $\mathbf{4 b}$ could not be analysed by this technique due to the lack of a suitable reference compound, it exhibited sufficient magnitude of downfield shifts in its $\mathrm{H}_{\mathrm{C}}$ protons to provide good quality data using a standard ${ }^{1} \mathrm{H}$ NMR titration protocol.

As shown by the anion association constants for 1-4 given in Table $\mathbf{1}$, the XB foldamers $\mathbf{1 b}-\mathbf{4 b}$ were found to be stronger halide and oxoanion receptors than their HB analogs. This difference is especially prominent in systems $\mathbf{3}$ and $\mathbf{4}$. This is because the $\mathrm{XB}$ receptors rely predominantly on the iodotriazole $\mathrm{XB}$ donors for anion affinity, whereas their $\mathrm{HB}$ analogues benefit in part from secondary $\mathrm{HB}$ donors at the phenylene rings next to the triazoles. ${ }^{10,11}$ Deletion of these binding elements as in 3a and 4a leads to fewer convergent HB interactions and consequently a large loss of anion affinity. The XB receptors, on the other hand, are tolerant to these modifications. Thus, the anthryl-terminated $\mathbf{3 b}$ displayed affinity for $\mathrm{Br}^{-}$and $\mathrm{I}^{-}$that was two orders of magnitude stronger than of 3a. Likewise, XB receptor $4 \mathbf{b}$ exhibited notable $K_{\mathrm{a}}$ values of up to $500 \mathrm{M}^{-1}$ in $1: 1$ $\mathrm{CDCl}_{3} /$ acetone- $d_{6}$, while $4 \mathrm{a}$ displayed almost no binding (too weak to be quantified).

Table 1 Association constants ${ }^{a} K_{\mathrm{a}}\left[\mathrm{M}^{-1}\right]$ for $\mathbf{1 - 4}$ with halides and oxyanions $^{a}$

\begin{tabular}{rrrrrrr}
\hline \multicolumn{1}{c}{$\mathrm{Cl}^{-}$} & \multicolumn{1}{c}{$\mathrm{Br}^{-}$} & $\mathrm{I}^{-}$ & $\mathrm{H}_{2} \mathrm{PO}_{4}{ }^{-}$ & \multicolumn{1}{c}{$\mathrm{AcO}^{-}$} & L-Tartrate \\
\hline $\mathbf{1 a}$ & $232(3)$ & $356(10)$ & $427(9)$ & $1244(83)$ & $69(1)$ & $331(3)$ \\
$\mathbf{1 b}$ & $433(44)$ & $600(46)$ & $1202(87)$ & $-{ }_{b}$ & $320(57)$ & $281(27)$ \\
2a & $466(18)$ & $740(29)$ & $960(46)$ & $2751(92)$ & $174(4)$ & $672(9)$ \\
2b & $592(59)$ & $902(76)$ & $2131(142)$ & $-{ }_{b}$ & $504(88)$ & $549(41)$ \\
3a & $20(2)$ & $15(1)$ & $24(1)$ & $87(11)^{c}$ & $-{ }^{d}$ & $64(1)$ \\
3b & $742(65)$ & $1235(79)$ & $2712(187)$ & $493(80)^{e}$ & $753(116)$ & $585(43)$ \\
4a & $-{ }^{d}$ & $-{ }^{d}$ & $-{ }^{d}$ & $37(3)$ & $-{ }_{d}$ & $-{ }^{d}$ \\
4b & $335(14)$ & $384(28)$ & $511(94)$ & $207(4)$ & $165(9)$ & $445(16)$
\end{tabular}

${ }^{a} 1: 1$ binding stoichiometry. All anions introduced as TBA salts; 1-3 studied in $\mathrm{CDCl}_{3} ; 4$ in $1: 1 \mathrm{CDCl}_{3} /$ acetone- $d_{6}(500 \mathrm{MHz}, 298 \mathrm{~K})$; [receptor] $=1.5 \mathrm{mM}$. Unless stated otherwise, $K_{\mathrm{a}}$ for $\mathbf{1 a}-\mathbf{4 a}$ were derived from $\mathrm{H}_{\mathrm{A}}$; for $\mathbf{4 b}$ from $\mathrm{H}_{\mathrm{C}}$; for $\mathbf{1 b} \mathbf{b} \mathbf{3} \mathbf{b}$ from $\mathrm{H}_{\mathrm{A}}$ of the reference compound 2a using the competition method. Uncertainties are given in parentheses. ${ }^{b}$ Could not be determined as HB foldamers are too strong $\mathrm{H}_{2} \mathrm{PO}_{4}{ }^{-}$binders to be used as reference compounds. ${ }^{c}$ Derived from $\mathrm{H}_{\mathrm{E}}$. ${ }^{d}$ Too weak to be quantified. ${ }^{e}$ Derived from $\mathrm{H}_{\mathrm{C}}$ using the standard ${ }^{1} \mathrm{H}$ NMR titration method. 
Comparing the $\mathrm{XB}$ foldamers, the anion binding strength is in the order $\mathbf{3 b}>\mathbf{2 b}>\mathbf{1 b}>\mathbf{4 b}$. This indicates that the wider spacing of the bis-iodotriazole arms in $\mathbf{4 b}$ leads to less effective alignment of its $\mathrm{XB}$ donors with halides and carboxylates. As expected, 2b exhibited 1.5-2 times higher $K_{\mathrm{a}}$ values than $\mathbf{1 b}$ due to its more electron-withdrawing termini, which is also observed in the HB analogues 1a and 2a.

The $\mathrm{XB}$ receptors displayed the order of selectivity $\mathrm{I}^{-}>$ $\mathrm{Br}^{-}>\mathrm{Cl}^{-} \approx \mathrm{AcO}^{-} \approx \mathrm{H}_{2} \mathrm{PO}_{4}{ }^{-}$, which suggests better hostguest size complementarity with larger halides. Additionally, neutral XB donors 1-4 do not display charge assistance that might favour binding of small, hard anions in cationic hosts. Interestingly, tartrate ${ }^{2-}>\mathrm{AcO}^{-}$selectivity was observed in $\mathrm{HB}$ receptors $\mathbf{1 a}-\mathbf{3 a}$ and $\mathrm{XB}$ receptor $\mathbf{4 b}$ but not in $\mathbf{1 b} \mathbf{b} \mathbf{3} \mathbf{b}$. This may indicate that with $\mathbf{1 b}-\mathbf{3 b}$, the anion binding cavity is too small to simultaneously bind both anionic groups in a dicarboxylate due to the large size of the four convergent iodine atoms. Increased spacing between the bis(iodotriazole) arms in $\mathbf{4 b}$ allows both carboxylate groups to be bound and induces dicarboxylate selectivity. This is also seen in HB analogues which have a less crowded anion binding site.

Single crystals of $\mathbf{3 b} \cdot \mathbf{N a I}$ suitable for X-ray structural analysis were obtained by combining $\mathbf{3 b}$ and excess $\mathrm{NaI}$ in $6: 4 \mathrm{CHCl}_{3} /$ acetone. + The structure (Fig. 3) shows the $\mathrm{XB}$ host encapsulating $\mathrm{I}^{-}$via four linear halogen bonds [C-I $\cdots \mathrm{I}^{-}$distances: 3.484(1)-3.574(2) $\AA$ (88-90\% of $\left.\Sigma r_{\text {vdw }}\right)^{21} \mathrm{C}-\mathrm{I} \cdots \mathrm{I}^{-}$angles: $\left.165.7(3)-178.3(3)^{\circ}\right]$. Due to the large size of the four iodine $\mathrm{XB}$ donor atoms the wrapping of the foldamer around the guest anion is less tight than in the analogous HB systems. ${ }^{22}$ The iodotriazoles are tilted by $29-54^{\circ}$ relative to the neighbouring phenylene rings and the $\mathrm{I}^{-}$guest is situated $3.01 \AA$ above the mean plane of the foldamer backbone. The $\mathrm{Na}^{+}$countercation is complexed by the triethylene glycol chain, with an acetone solvate molecule and a triazole $\mathrm{N}^{3}$ atom from an adjacent molecule completing its coordination sphere.

The XB receptors $\mathbf{3 b}$ and $\mathbf{4 b}$ displayed an intense fluorescence in $375-525 \mathrm{~nm}$ region arising from the emission of anthracene termini (Fig. 4). In $\mathbf{3 b}$ a large increase in emission intensity, without changes in wavelength, occurred upon addition of TBABr.
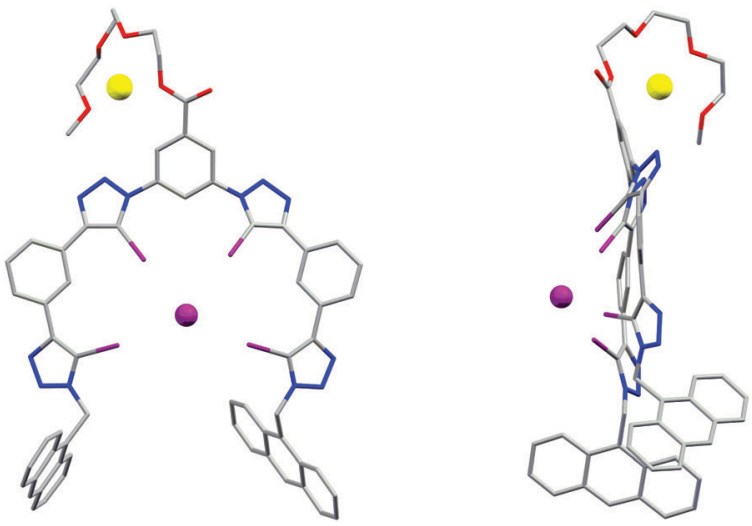

Fig. 3 X-ray crystal structure of $\mathbf{3 b}$. Nal showing the face-on (left) and side-on (right) view, visualising the folding of the receptor in a capped configuration.
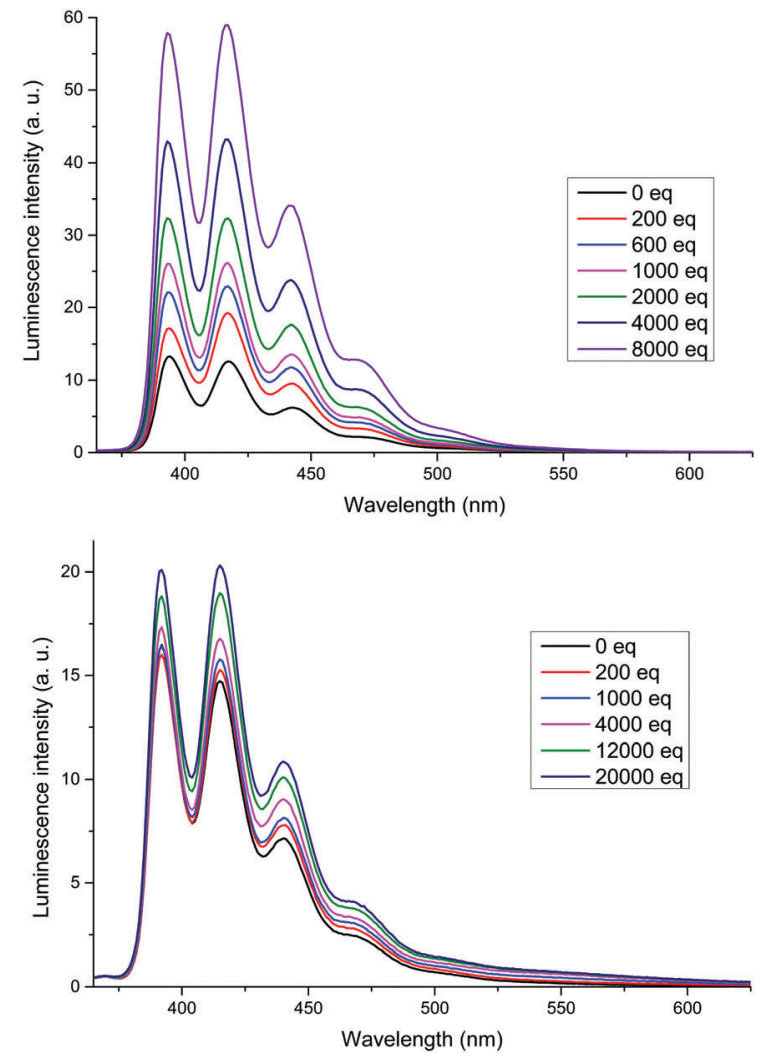

Fig. 4 Emission spectra of $\mathbf{3 b}$ (top) and $\mathbf{4 b}$ (bottom) titrated with TBABr. Host concentration: $1 \mu \mathrm{M}$ in $\mathrm{CHCl}_{3}(\mathbf{3 b})$ or $1: 1 \mathrm{CHCl}_{3}$ /acetone (4b), $\lambda_{\mathrm{ex}}=350 \mathrm{~nm}$.

A small increase was also observed for $\mathbf{4 b}$; the most significant change occurred in the emission peak at $420 \mathrm{~nm}$ for both receptors. The overall increase in fluorescence intensity upon anion binding is most probably due to conformational rigidification of the receptor which suppresses non-radiative decay pathways. Thus, the larger fluorescence enhancement in $\mathbf{3 b}$ is likely due to $\mathbf{3 b}$ being less disordered in its bound state than $\mathbf{4 b}$. As seen in the solid state structure of $\mathbf{3 b} \cdot \mathbf{N a I}$, the anthracene termini are too far from each other for effective intramolecular $\pi$-stacking which accounts for the absence of excimer emission. ${ }^{23}$

Table 2 Association constants $K_{\mathrm{a}}\left[\mathrm{M}^{-1}\right]$ for $\mathbf{4} \mathbf{b}$ with enantiomers of chiral carboxylates $^{a}$

\begin{tabular}{lll}
\hline & $K_{\mathrm{a}}{ }^{b}$ & $K_{\mathrm{D}} / K_{\mathrm{L}}$ \\
\hline L-Boc-Ala & $336(23)$ & $0.79(0.17)$ \\
D-Boc-Ala & $265(52)$ & \\
L-Boc-Leu & $287(38)$ & $1.52(0.21)$ \\
D-Boc-Leu & $436(21)$ & $1.69(0.12)$ \\
L-Boc-Trp & $200(14)$ & $1.29(0.04)$ \\
D-Boc-Trp & $337(4)$ & \\
L-Tartrate & $725(6)$ & $0.92(0.15)$ \\
D-Tartrate & $932(28)$ & \\
L-Glutamate & $1483(220)$ & \\
D-Glutamate & $1363(99)$ &
\end{tabular}

${ }^{a}$ All anions were introduced as TBA salts. All titrations were undertaken in $1: 1 \mathrm{CDCl}_{3} /$ acetone- $d_{6}(500 \mathrm{MHz}, 298 \mathrm{~K})$. Uncertainties are given in parentheses. ${ }^{b}$ Determined from titration data monitoring $\mathrm{H}_{\mathrm{D}}$. 
Chiral XB $\mathbf{4 b}$ receptor was titrated with both enantiomers of Boc-Ala, Boc-Leu, Boc-Trp, Glu and tartrate as TBA salts. The association constant values shown in Table 2 reveal varying degrees of chiral discrimination were observed with different anions. The greatest difference in affinity was observed for tryptophan $\left(K_{\mathrm{D}} / K_{\mathrm{L}}=1.69\right)$, followed by leucine and alanine, which correlates with the steric bulk of the amino acid residue. In the case of the dicarboxylate guests, a modest degree of discrimination was seen for tartrate while no difference was observed for glutamate. This is once again consistent with the steric factors of guest anions.

In summary a series of novel neutral tetrakis(5-iodo-1,2,3triazole) foldamers $\mathbf{1 b}-\mathbf{4 b}$ was prepared and evaluated as halogen bonding anion receptors. Importantly, compared to their $\mathrm{HB}$ analogues 1a-4a, the XB foldamers showed enhanced anion affinities, with a general preference for binding heavier halides over oxoanions. The advantage of $\mathrm{XB}$ for anion binding is especially evident in $\mathbf{3 b}$ and $\mathbf{4 b}$ where the $\mathrm{HB}$ analogues $\mathbf{3} \mathbf{a}$ and $\mathbf{4 a}$ displayed very weak affinities due to the deletion of secondary HB donors, while the $\mathrm{XB}$ foldamers $\mathbf{3 b}$ and $\mathbf{4 b}$ remained effective as anion receptors. The incorporation of anthracene and chiral BINOL groups into the XB foldamer structure design demonstrated fluorescent anion sensing and chiral discrimination capabilities which are currently under further investigation.

We thank the EPSRC centre for Doctoral Training in Synthesis for Biology and Medicine (EP/L015838/1), the Agency for Science, Technology and Research (A*STAR), Singapore, and the European Research Council (FP7/2007-2014, ERC Advanced Grant Agreement No. 267426) for financial support, Diamond Light Source for an award of beamtime on I19 (MT13639) and the beamline scientists for technical support.

\section{Notes and references}

\$ Single crystal diffraction data were collected at 100(2) K using a custom-built Crystal Logic diffractometer and synchrotron radiation $(\lambda=0.6889 \AA)$ at Diamond Light Source, beamline I19. ${ }^{24}$ Unit cell parameter determination and data reduction were carried out using CrysAlisPro. The structures were solved by charge-flipping with SUPERFLIP $^{25}$ and refined by full matrix least squares on $F^{2}$ using CRYSTALS. $^{26-28}$ Full refinement details are given in the ESI. $\dagger$ Single crystal data: $\mathrm{C}_{64} \mathrm{H}_{48} \mathrm{I}_{5} \mathrm{~N}_{12} \mathrm{NaO}_{5} \mathrm{Zn} \cdot 4\left(\mathrm{C}_{3} \mathrm{H}_{6} \mathrm{O}\right), M_{\mathrm{r}}=1954.99$; triclinic, $P \overline{1}$; $a=14.3220(4) \AA, b=17.7665(5) \AA, c=17.7815(5) \AA, \alpha=113.335(2)^{\circ}$, $\beta=100.303(2)^{\circ}, \gamma=93.903(2)^{\circ}, V=4038.8(2) \AA^{3}$; data, restraints, parameters: $11420 / 955 / 928 ; R_{\mathrm{int}}=0.195$, final $R_{1}=0.100, \mathrm{w} R_{2}=0.281$ $\left(F^{2} ;[I>2 \sigma(I)]\right) ; \Delta \rho_{\min \text { max }}=-3.28,+2.38 \mathrm{e}^{-3}$. CCDC 1529410 .

1 G. Cavallo, P. Metrangolo, R. Milani, T. Pilati, A. Priimagi, G. Resnati and G. Terraneo, Chem. Rev., 2016, 116, 2478-2601.

2 P. Metrangolo, F. Meyer, T. Pilati, G. Resnati and G. Terraneo, Angew. Chem., Int. Ed., 2008, 47, 6114-6127.

3 L. C. Gilday, S. W. Robinson, T. A. Barendt, M. J. Langton, B. R. Mullaney and P. D. Beer, Chem. Rev., 2015, 115, 7118-7195.

4 S. Schindler and S. M. Huber, Halogen Bonding Ii: Impact on Materials Chemistry and Life Sciences, 2015, vol. 359, pp. 167-203.

5 T. M. Beale, M. G. Chudzinski, M. G. Sarwar and M. S. Taylor, Chem. Soc. Rev., 2013, 42, 1667-1680.

6 N. L. Kilah, M. D. Wise, C. J. Serpell, A. L. Thompson, N. G. White, K. E. Christensen and P. D. Beer, J. Am. Chem. Soc., 2010, 132, 11893-11895.

7 R. Tepper, B. Schulze, M. Jager, C. Friebe, D. H. Scharf, H. Gorls and U. S. Schubert, J. Org. Chem., 2015, 80, 3139-3150.

8 B. Schulze and U. S. Schubert, Chem. Soc. Rev., 2014, 43, 2522-2571.

9 Y. L. Li and A. H. Flood, J. Am. Chem. Soc., 2008, 130, 12111-12122.

10 H. Juwarker, J. M. Lenhardt, D. M. Pham and S. L. Craig, Angew. Chem., Int. Ed., 2008, 47, 3740-3743.

11 H. Juwarker, J. M. Lenhardt, J. C. Castillo, E. Zhao, S. Krishnamurthy, R. M. Jamiolkowski, K. H. Kim and S. L. Craig, J. Org. Chem., 2009, 74, 8924-8934.

12 J. Shang, W. Zhao, X. Li, Y. Wang and H. Jiang, Chem. Commun., 2016, 52, 4505-4508.

13 A. Brown and P. D. Beer, Chem. Commun., 2016, 52, 8645-8658.

14 C. J. Massena, N. B. Wageling, D. A. Decato, E. Martin Rodriguez, A. M. Rose and O. B. Berryman, Angew. Chem., 2016, 55, 12398-12402.

15 L. Y. You, S. G. Chen, X. Zhao, Y. Liu, W. X. Lan, Y. Zhang, H. J. Lu, C. Y. Cao and Z. T. Li, Angew. Chem., Int. Ed., 2012, 51, 1657-1661.

16 F. Zapata, A. Caballero, P. Molina, I. Alkorta and J. Elguero, J. Org. Chem., 2014, 79, 6959-6969.

17 J. Y. C. Lim, I. Marques, L. Ferreira, V. Felix and P. D. Beer, Chem. Commun., 2016, 52, 5527-5530.

18 T. R. Chan, R. Hilgraf, K. B. Sharpless and V. V. Fokin, Org. Lett., 2004, 6, 2853-2855.

19 M. J. Hynes, J. Chem. Soc., Dalton Trans., 1993, 311-312.

20 J. M. Daniel, S. D. Friess, S. Rajagopalan, S. Wendt and R. Zenobi, Int. J. Mass Spectrom., 2002, 216, 1-27.

21 A. Bondi, J. Phys. Chem., 1964, 68, 441-451.

22 Y. R. Hua, Y. Liu, C. H. Chen and A. H. Flood, J. Am. Chem. Soc., 2013, 135, 14401-14412.

23 K. Ghosh, A. R. Sarkar, A. Ghorai and U. Ghosh, New J. Chem., 2012, 36, 1231-1245.

24 H. Nowell, S. A. Barnett, K. E. Christensen, S. J. Teat and D. R. Allan, J. Synchrotron Radiat., 2012, 19, 435-441.

25 L. Palatinus and G. Chapuis, J. Appl. Crystallogr., 2007, 40, 786-790. 26 P. W. Betteridge, J. R. Carruthers, R. I. Cooper, K. Prout and D. J. Watkin, J. Appl. Crystallogr., 2003, 36, 1487.

27 P. Parois, R. I. Cooper and A. L. Thompson, Chem. Cent. J., 2015, 9, 30.

28 R. I. Cooper, A. L. Thompson and D. J. Watkin, J. Appl. Crystallogr., 2010, 43, 1100-1107. 